\title{
LOS PRINCIPIOS DE DERECHO AMBIENTAL, SU NATURALEZA Y SUS RELACIONES CON EL DERECHO INTERNACIONAL MARÍTIMO. UN CAMBIO PARA LOS LEGISLADORES NACIONALES*
}

\author{
Franc MAES**
}

\begin{abstract}
RESUMEN: El artículo establece criterios básicos para distinguir las normas de derecho internacional de los principios de derecho internacional, los principios de derecho ambiental, así como los principios del derecho. Efectúa el autor un análisis de las principales normas y las discusiones más importantes en estas materias. Finalmente el derecho internacional marítimo es objeto de estudio y análisis en sus elementos relevantes. Referencias al derecho belga son incluidas en el artículo.
\end{abstract}

ABSTRACT: The article explores various concepts of the term "Principles of International Law" and "Principles of International Environmental Law". As well, the application of such concepts taking into account the words used in international legal texts, terms like "shall or should" and various other possible ways of application of international legal rules binding States, particularly in the Belgian context have been tackled by the author. There is not a specific answer to the questions put forth in the beginning of the article.

RÉSUMÉ: L'article établit des critères de base pour faire la distinction entre, d'une part, les normes du Droit International et d'autre part; les Principes de Droit International, les Principes de Droit de l'environnement et les Principes de Droit. L'auteur analyse les principales normes et les débats les plus importants sur ces thèmes. Le Droit International Maritime est également analysé. Des références au droit belge sont incluses dans l'article.

* Este texto fue publicado en Sheridan, Maurice y Lavrysen, Luc (eds.), Environmental Law. Principles in Practice, Bruselas, Bruyllant, 2002. Traducido y adaptado, con la autorización del autor, por Sergio Peña-Neira, profesor en la Universidad del Mar, Valparaíso y magister en relaciones internacionales por la Universidad de Ámsterdam, Países Bajos.

** Profesor de derecho internacional público de la Universidad de Ghent, Bélgica. 
SuMARIO: I. Introducción. II. Fuentes de derecho internacional. III. ¿Cuán útiles son los "principios de derecho internacional"? IV. Hacia la codificación global de los "principios de derechos del medio ambiente". V. Principios de derecho ambiental y el derecho del mar. VI. La protección del medio ambiente en Europa y en Bélgica. VII. Conflictos entre diferentes principios de derecho internacional. VIII. Conclusión.

\section{INTRODUCCIÓN}

La codificación de "principios de derecho ambiental" en convenciones internacionales, en decisiones de organismos internacionales y en la legislación nacional se ha desarrollado desde $1992 .{ }^{1}$ La mayoría de estos "principios de derecho ambiental", sin embargo, no son nuevos. Ellos han sido aceptados anteriormente en instrumentos internacionales denominados Soft Law, ${ }^{*}$ tales como, declaraciones, recomendaciones de organizaciones internacionales $\mathrm{y}$, del mismo modo, en las convenciones en diversas regiones del globo. La Declaración de Río de Janeiro sobre Desarrollo y Medio Ambiente (1992) situó tales "principios de derecho ambiental" en las relaciones internacionales. En el caso del legislador nacional, que pretende implementar "principios de derecho ambiental", es importante conocer el verdadero sentido de los mismos y saber si los "principios de derecho internacional" aceptados e incorporados en los "principios de derecho ambiental" son sólo "principios de derecho" o, a la vez, "principios de política pública". Del mismo modo y, desde otra perspectiva, el legislador de cada país debe definir si tales "principios de derecho ambiental" deben ser aplicados de manera general o de manera específica. Con el fin de tener una idea más clara en torno a este tema, es

1 En Bélgica: Flemish Decree on Principles of Environmental Policy, 5 de abril de 1995, BOJ, 3 de junio de 1999; véase para el decreto de la región flamenca: Bocken, H. y Ryckbost, D. (eds.), Codification of Environmental Law. Draft on Environmental Policy, Londres-The Hague-Boston, Kluwer Law International, 1996, pp. 3 y 4; véase también de Sade, N., Les principes du pollueur-payeur, de prévention et de précaution, Bruselas, Bruyllant, 1999, pp. 59, 64, 107, 114, 120, 166.

* Soft Law carece de una definición concreta en derecho internacional pero podría conceptualizarse como "una serie de normas no-jurídicas y no-obligatorias que sirven de guía u orientación para el actuar de los sujetos de derecho internacional". En torno a un concepto sobre el tema, véase Mazuelos Bellido, A., "Soft Law: ¿Mucho ruido y pocas nueces?", Revista Electrónica de Estudios Internacionales, núm. 8, www.reei.org (N. del T.). 
posible formular ciertas preguntas, que se encuentran relacionadas a las materias indicadas precedentemente, tales como: ¿Poseen estos principios de derecho ambiental aplicación directa en la legislación nacional? ¿Requieren ellos una acción adicional de parte del legislador para hacerlos operativos a través de, quizás, normas jurídicas nacionales más específicas?

Este artículo no pretende encontrar soluciones específicas. Así, desde la perspectiva del derecho internacional, es posible indicar que cualquiera evaluación dependerá de lo que sea considerado por los autores como "derecho internacional". Diferentes escuelas de pensamiento tienen diferentes visiones doctrinales acerca de lo que es derecho internacional y, más precisamente, la cualidad intrínseca de lo que es un sistema jurídico, la interdependencia de éste con el poder y la conducta de los Estados en un tiempo dado. ${ }^{2}$ Estas diferentes visiones pueden ser divididas en "aproximación hacia la norma" y "aproximación hacia el proceso". La "aproximación hacia el proceso" hace una clara distinción entre lex lata y lege ferenda, en cambio, en "aproximación hacia la norma" tal distinción es irrelevante. ${ }^{3}$ Nadie duda que una de las posibles vías de conceptualización del derecho internacional es ser considerado como un proceso continuo de creación de normas provenientes de los principios y de conductas de sus sujetos para lograr una administración efectiva en las relaciones entre miembros de la comunidad internacional, principalmente Estados, e incluyendo organizaciones internacionales e individuos.*

2 Para una visión general y referencias, véase Hoof, G. J. H. van, Rethinking the Sources of International Law, Deventer, Kluwer Law International, 1983, pp. 17-56; Higgins, R., Problems and Process of International Law and how we use it, Oxford, Clarendon Press, 1994, pp. 1-16; Steiner, H. J., "International Law, Doctrine and Schools of Thought in the Twientieth Century", en Bernhardt, R. (ed.), Encyclopedia of Public International Law, Amsterdam, Elsevier, 1995, vol. II, pp. 1216-1227; véase, en materia de discusión, Cassese A., Weiler, J. (eds.), Change and Stability in International Law-Making, Berlín, Walter de Gruyter, 1988.

3 Véase Cheng, Bin, "Epilogue on the Nature and Sources of International Law", en id. (ed.), International Law: Teaching and Practice, Londres, Stevens y Sons, 1982, pp. 204-209.

* La "aproximación hacia la norma" tiene relación con la interpretación e implementación de las normas jurídicas internacionales, sea en el plano internacional, donde derecho y obligaciones juegan un rol fundamental, o en el plano nacional, donde los Estados se encuentran obligados por tales derechos y obligaciones ( N. del T.). 


\section{FUENTES DE DERECHO INTERNACIONAL}

El más importante punto de partida en la manera de identificar el derecho internacional aplicable en las relaciones entre Estados es la intención de los Estados. ${ }^{4}$ El consentimiento no es necesario expresarlo siempre. La falta de respuesta, oponiéndose a ciertos actos en ciertas situaciones, cuando es aplicable a un Estado, puede ser interpretado como un consentimiento implícito para obligar. ${ }^{5}$

El valor legal de los "principios de derecho internacional", ya que ellos generan efectos legales y puede ser aplicado por la fuerza de la ley (enforcement $)^{*}$ depende de varios factores que se relacionan principalmente con las "fuentes de derecho internacional" y el lenguaje utilizado. Es necesario, primeramente, definir la fuente en que el principio ha sido expresado. De acuerdo al artículo 38, primer párrafo, del Estatuto de la Corte Internacional de Justicia, son tres las fuentes importante para definir el sentido de un "principio de derecho internacional" y sus efectos: los tratados internacionales, la costumbre internacional y los "principios generales del derecho" reconocidos por las "naciones civilizadas". Desde la "descolonización", todos los miembros de las Naciones Unidas son consideradas "naciones civilizadas". Una cuarta fuente son las decisiones judiciales y las enseñanzas de publicistas cualificados en varias naciones. La cuarta fuente es subsidiaria de las otras tres. Aunque el artículo 38 párrafo primero sólo obliga a la Corte Internacional de Justicia, las tres fuentes primeramente indicadas han sido consideradas el punto de partida para la discusión doctrinal acerca de derecho internacional y pueden ser estimadas como la mejor definición de normas internacionales. ${ }^{6}$

Si bien los tratados internacionales crean derecho entre las partes a los mismos, el derecho consuetudinario internacional y los "principios de

4 Lotus case (1927) Permanent Court of International Justice (PCIJ), serie A, núm. 10, 18; Barcelona Traction Case, International Court of Justice (ICJ) Reports, 1970, 47; Nicaragua Case, ICJ Reports, 1986, p. 135.

5 Müller, J. P. y Cottier, T., “Acquiescience”, en Bernhardt, R. (ed.), EPIL, vol. 1, 1992, p. 14.

* La palabra enforce posee un significado especial en materia jurídica dentro del derecho anglosajón, implica una real aplicación de las normas jurídicas en un determinado lugar o en una determinada área $(N$. del $T$.).

6 Mosler, H., "General Principles of Law", en Bernhardt, R. (ed.), EPIL, vol. II (1995), nota 2, p. 515. 
derecho internacional" pueden crear derecho para todos los Estados. No hay una jerarquía entre las fuentes, con la excepción del caso de jus cogens. ${ }^{7}$ Jus cogens es una regla básica o un principio de derecho internacional que no admite derogación alguna. ${ }^{8}$ Es una obligación que compele a todos los Estados con relación a la comunidad internacional, como por ejemplo las obligaciones de no permitir esclavitud, piratería o genocidio. ${ }^{9}$ Jus cogens es posible de ser encontrado tanto en el derecho de los tratados, en la costumbre internacional y en los "principios de derecho internacional". Parece lógico que la Corte Internacional de Justicia y los especialistas estudien los tratados internacionales, ya que la intención de las partes y sus obligaciones han sido expresadas en ellos generalmente de manera más clara. ${ }^{10}$ Normalmente, la existencia de un "principio de derecho internacional" perteneciente a la costumbre internacional o cuando sea parte de un principio de derecho internacional (general) es más difícil de probar, excepto cuando la prueba ha sido conocida por y se ha dejado constancia de la misma en una corte internacional, un tribunal nacional o el principio ha sido explícitamente aceptado como tal por los Estados.

7 Nicaragua Case, ICJ Reports, 1986, pp. 94, 95 y 96, párrs. 175, 177, 178 y 179; see also Akehurst, M., "The Hierarchy of the Sources of International Law", 47 British Yearbook of International Law (BYIL), 1974-1975, pp. 273-279; Villiger, M., Customary International Law and Treaties, Dordrecht, Martinus Nijhoff, 1985, p. 35; American Law Institute, Restatement of the Foreign Relations Law of the United States, vol. I, St. Paul Minn., 1987, p. 102 (j); Danilenko, G. M., Law-Making in the International Community, Dordrecht, Martinus Nijhoff, 1993, pp. 110-115.

8 Artículo 53 de la Convención de Viena sobre el Derecho de los Tratados de 23 de mayo de 1969 indica: "Es nulo todo tratado que, en el momento de su celebración, esté en oposición con una norma imperativa de derecho internacional general. Para los efectos de la presente convención, una norma imperativa de derecho internacional general es una norma aceptada y reconocida por la comunidad internacional de Estados en su conjunto como norma que no admite acuerdo en contrario y que sólo puede ser modificada por una norma ulterior de derecho internacional general que tenga el mismo carácter". Ratificado por Bélgica el 18 de febrero de 1993.

9 Véase Frowein, J. A., "Jus Cogens", en Bernhardt, R. (ed.), EPIL, vol. III, 1997, pp. 65-69; Kolb, R., "The Formal Source of Ius Cogens in Public International Law", Australian Journal of Public International Law, 1998, pp. 69-106.

10 Akehurst, M., op. cit., nota 7, p. 274; véase, por ejemplo: Gabcikovo-Nagymaros Project (Hungría-Eslovakia) donde la corte principalmente basa su criterio en el original del proyecto del acuerdo de 1977, Sentencia, ICJ Reports, 1997. 
Para probar la existencia de la costumbre internacional en otros casos resulta necesario encontrar apoyo para los "principios de derecho internacional" tanto en la "práctica de los Estados" (usus) como en la opinio juris. La "práctica de los Estados" es evidencia de la conducta y actuación de los Estados mismos, incluyendo cualquier acto o declaración por un Estado de donde lo que se entiende por costumbre internacional puede ser deducida. Por ejemplo, actos físicos, demandas, declaraciones in abstracto, leyes nacionales, sentencias nacionales y omisiones. ${ }^{11} \mathrm{La}$ práctica del Estado en las relaciones internacionales debe ser uniforme y continua. ${ }^{12}$ Opinio juris es la convicción de que las prácticas antes mencionadas de los Estados reflejan obligaciones legales y así se pueden distinguir de otras normas que obligan y de otras reglas de conducta. Además, la costumbre internacional establece obligaciones para todos los Estados, con excepción de aquellos que han objetado persistentemente una práctica y sus consecuencias legales. ${ }^{13}$ En otras palabras, un "objetor permanente" no puede evitar el desarrollo de una regla de costumbre internacional, pero puede lograr no ser obligado por ella. ${ }^{14}$ Sin embargo, donde una norma de costumbre internacional se desarrolla y se convierte en una norma de jus cogens, los "objetores permanentes" se encuentran obligados por esta norma jurídica debido a la naturaleza del jus cogens.

11 Akehurst, M., "Custom as a source of International Law", 47 BYIL 53.

12 Asylum Case, ICJ Reports, 1950, p. 277; North Sea Continental Shelf Case, ICJ Reports, 1969, p. 44; Continental Shelf Case (Libyan Arab Jamarihiya-Malta), ICJ Reports, 1985, pp. 29-30, párr. 27; Nicaragua Case, ICJ Reports, 1986, p. 97, párrs. 183-184, 108-109, 207; Thirlway, H. W. A., International Customary Law and Codification, Leiden, A. W. Sijthoff, 1972, pp. 145-146; Mosler, H., The International Society as a Legal Community, Alphen aan den Rijn, Sijthoff and Nordhoff, 1980, pp. 107-115; Brownlie, I., Principles of Public International Law, Oxford, Clarendon Press, 1977, pp. 6-10; Hoof, G. J. H. van, op. cit., nota 2, p. 87; Danilenko, G. M., op. cit., nota 7, p. 81; Wolfke, K., "Some persistent Controversies Regarding Customary International Law", 24 Nehterlands Yearbook of International Law (NYIL), vol. I, 1993, pp. 40-51, párr. 51; Higgins, R., op. cit., nota 2, pp. 18 y 19.

13 Véase Charney, J. I., "The persistent objector Rule and the Development of Customary International Law", 56 RVIL 24, 1985.

14 Akehurst, M., A Modern Introduction to International Law, Londres, George Allen and Uwin, 1977, p. 53; Brownlie, I., op. cit., nota 12, pp. 10 y 11; American Law Institue, op. cit., nota 7, p. 102 (d); Szas, P. C., "International Norm-Making", en Brown Weiss, E. (ed.), Environmental Change and International Law, Tokio, United Nations University Press, 1992, p. 67; Danilenko, G. M., op. cit., nota 7, pp. 106, 109-113; Wolfke, K., op. cit., nota 12, p. 66. 
Los Estados se encuentran obligados desde la aceptación y el reconocimiento de una norma de jus cogens por la comunidad internacional, aunque se debe hacer presente que la comunidad internacional raramente reconoce una norma de jus cogens como tal, fácilmente.

En la doctrina, el sentido de los elementos: práctica estatal y Opinio Juris, que constituyen la costumbre internacional, no ha sido resuelto a través de un acuerdo o, en su caso, no se ha explicado claramente si pueden separarse. ${ }^{15}$ Para Rijpkema: "El caso Nicaragua exhibe que esos requisitos [práctica estatal y Opinio Juris] no serán obtenidos en todos los casos, pero sólo en el caso en que la existencia de una norma de costumbre internacional es discutida por una de las partes en el caso". ${ }^{16} \mathrm{Al}$ enfrentar una disputa acerca de la existencia de una norma internacional basada en la costumbre internacional entre Estados, el Estado que cree en la norma debe probar su existencia. Además la costumbre internacional existe también como costumbre de parte de una región del planeta y que obliga a países en una determinada región del mundo. ${ }^{17}$ En el preámbulo de la Convención para la Protección del Medio Ambiente del Atlántico Nor-Este (París, 1992), ${ }^{18}$ las partes han decidido: "Llamar las normas relevantes de costumbre internacional reflejada en la parte XII de la Convención de Naciones Unidas sobre Derecho del Mar y, en particular, artículo 197 acerca de cooperación global y regional para la protección y preservación del ambiente marino".

Esta declaración es significativa desde una perspectiva regional. Sin embargo, no es claro si otros Estados o regiones poseen la misma opi-

15 Véase Bin Cheng, "United Nations Resolution on Outer Space: 'Instant' International Customary Law", 5 Indian Journal of International Law (IJIL) 46, 1965; D'Amato, A., The Concept of Custom in International Law, Ithaca y Londres, Cornwell University Press, 1971, pp. 74-87; Bin Cheng (ed.), op. cit., nota 3, p. 223; Bos, M., "The identification of Custom in International Law", 25 German Yearbook of International Law (GYIL) 9, 1982; Wolfke, K., op. cit., nota 12; Elias O., "The Nature of the Subjective Element in Customary International Law", en 44 International and Comparative Law Quarterly (ICLQ), 1995, p. 501.

16 Rijpkema, P. P., "Customary International Law in the Nicaraguan Case", 20 NYIL 98, 1989.

17 “Asylum Case", ICJ Reports, 1950, p. 276; "Right to Passage over Indian Territory Case", ICJ Reports, 1960, p. 39.

18 Convención para la Protección del Medio Ambiente Marino del Atlántico Nor-Este, París, 22 de septiembre de 1992, 32, International Legal Materials (ILM), 1960-1992. 
nión. Convenciones regionales de reciente data que buscan proteger el medio ambiente marino como la del Mar Báltico (1992), el Mar Mediterráneo (de 1976 enmendada en 1995) y el Mar Negro (1992) no mencionan a la costumbre internacional como un reflejo de la Convención sobre Derecho del Mar de Naciones Unidas en su parte XI. ${ }^{19}$

Para probar la existencia de un "principio de derecho internacional" se ha recurrido, principalmente, a los mismos medios de prueba para normas jurídicas de la costumbre internacional, aunque ésta no sea imperativa.

El concepto de "principios generales del derecho" implica varias significados. ${ }^{20} \mathrm{El}$ primer significado se refiere sólo a los "principios generales del derecho" aplicados en el derecho nacional. El segundo significado extiende el concepto de principios a aquellos que poseen sus orígenes directamente en relaciones legales de carácter internacional y los principios que serán aplicados generalmente en todos los casos del mismo tipo que emergen en el derecho internacional (por ejemplo, el principio de no-intervención). El tercer significado incluye el derecho reconocido en todas las relaciones, independientemente del orden jurídico al cual ellas pueden pertenecer, pudiendo ser derecho nacional o derecho internacional, así como el orden interno de organismos internacionales y de cualquier otro sistema legal autónomo. Estos principios son indispensables para el buen funcionamiento de las relaciones legales (por ejemplo, buena fe, pacta sunt servanda). Finalmente, hay principios de lógica jurídica que determinan las consecuencias resultantes de las interrelaciones de las dos relaciones legales (por ejemplo, lex specialis derogat legi generali y lex posteriori derogat legi priori). ${ }^{21}$ En este capítulo, "principios de derecho

19 United Nations Convention on the Law of the Sea, Montego Bay, 10 de diciembre de 1982, 21, ILM, 1982, p. 1261.

20 Véase para un visión en artículos doctrinales: Parry, C., The sources and Evidences of International Law, Manchester, Manchester University Press, 1965, pp. 83-91; Lammers, J. G., "General Principles of Law Recognised by Cicilised Nations", en Kalhoven, F. A. O. (ed.), Essays on the Development of the International Legal Order, en Memory of Haro T. Van Panhuys, Alphen a/d Rijn, Sithof y Noordhoff, 1980, pp. 53-75; Vitanyi, B., "Les positions doctrinales concernant les sens de la notion des 'principes generaux' de droit reconnus par les nations civilices", 86 Revue Genérale de Droit International Public (RGDIP), 1982, pp. 45-116; Hoof, G. J. H. van, op. cit., nota 2, pp. 131-150; Danilenko, G. M., op. cit., nota 7, pp. 173-189.

21 Mosler, H., op. cit., nota 12, pp. 69-74, 71-72; Mosler, H., "General Principles of Law”, en Bernhardt, R. (ed.), EPIL, vol. II, 1995, nota 6, pp. 511 y 512. 
ambiental" son considerados bajo la segunda definición, lo cual significa principios que emergen o tienen su origen directamente en el derecho internacional.

Más allá de las fuentes indicadas en el Estatuto de la Corte Internacional de Justicia, es posible encontrar derivaciones de las principales fuentes de derecho internacional. Por ejemplo, en este grupo es posible encontrar las decisiones de organizaciones internacionales que obligan jurídicamente, siempre y cuando los estatutos de la respectiva organización establezcan tal obligación. Las Naciones Unidas, el Consejo de Seguridad, las Comunidades Europeas (EC) y OSPAR Commission (comisión bajo el mandato de la Convención de París de 1992)22 pueden tomar decisiones obligatorias desde el momento en que sus órganos institucionales derivan su autoridad legal del tratado y son parte del derecho de los tratados.

Adicionalmente, en la doctrina es posible encontrar referencia a la denominada Soft Law. ${ }^{23}$ Soft Law tiene dos sentidos o alcances. El primer sentido se refiere a la fuente, es decir, al hecho de que se está tratando de instrumentos que no son jurídicos como las "recomendaciones" y las "guías"* de organizaciones internacionales o "declaraciones de jefes de Estado o ministros". La segunda se refiere a la esencia del lenguaje; es decir, las normas o "práctica del Estado" en un tratado cuestionado pueden ser imprecisas y no son o no hacen posible una obligación jurídicamente obligatoria. En este último caso, no cabe duda de la naturaleza obligatoria de la fuente en sí misma, es decir, existe una norma jurídica obligatoria. Sin embargo, la obligación no está claramente establecida y es débil en su expresión, por ejemplo, por el uso de las palabras como "apropiadas" o "si es posible".

22 Véase infra notas 72 a 81 en las pp. 213-215. Véase también Hey, E. et al., "The Paris Convention for the Protection of the Marine Environment of the North-East Atlantic: A Critical Análisis", 8 The International Journal of Marine and Coastal Law (IJMCL), 1993, pp. 39 y 40.

23 Véase acerca de "Soft Law": Weil, P., "Towards Relative Normativity in International law", 77 American Journal of International Law (AJIL), 1983, p. 413; Gruchalla-Wesierski, T., "A Framework for Understanding 'Soft Law", 30 McGill Law Journal, 1984, p. 37; Chinkin, C. M., "The Challenge of Soft law: Development and Change in International Law", 38 ICLQ 1989, p. 850. Dupuy, P. M., "Soft Law and the international Law on the Environment", 12 Michigan Journal of International Law, 1991, p. 420.

* La palabra inglesa guideline ha sido traducida en esta parte como "guía" (N. del T.). 
Soft Law, en el primer sentido, es importante para el desarrollo de Hard Law, y puede ser una indicación de "práctica del Estado" en status nascendi. A veces la referencia hacia Soft Law es usada como parte de la evidencia de práctica estatal que puede apoyar la existencia de una regla de costumbre jurídica. Una parte significativa de derecho internacional del medio ambiente consiste en principios que carecen de legalidad o simples principios de políticas públicas que los Estados observan, aunque no existan sanciones que puedan ser legalmente aplicadas en el caso de inobservancia. En cambio, presión política y moral puede ser utilizada para obligar.

\title{
III. ¿CUÁN ÚTILES SON LOS "PRINCIPIOS DE DERECHO INTERNACIONAL"?
}

En general, los "principios de derecho internacional" pueden dar lugar a normas específicas o pueden ser los productos de inducción de normas específicas. ${ }^{24}$ Para Schwarzenberger, 25 "principios de derecho internacional" son:

\begin{abstract}
Abstracciones de carácter no obligatorio de normas jurídicas de derecho internacional más o menos cercanas, que pretenden ser obligatorias dentro de sus límites normativos. Estas normas pueden ser deducidas inductivamente a través de una referencia al proceso de creación de normativa jurídica y los órganos del Estado que determina existencia del derecho.* De acuerdo a esta distinción en el derecho internacional actualmente existente como diferente al derecho internacional en la creación o formación del mismo, "nuevos" principios pueden ser abstraídos sólo de normas jurídicas que obligan y el carácter de obligatorio de las normas jurídicas depende del cumplimiento con las normas procesales y los órganos establecidos en el Estatuto de la CIJ de 1945.
\end{abstract}

24 Schwarzenberger, G., The Inductive Approach to International Law, Londres, Stevens y Sons, 1965 , pp. 72-74.

25 Schwarzenberger, G., "Complexities of the Distinction Between Old and New International Law", en Pathak, R. S. y Dhokalia, R. P. (eds.), International Law in Transition. Essays in Memory of Judge Nagendra Singh, Dordrecht, Martinus Nijhoff, 1992 , p. 23.

* Se puede mencionar al Poder Legislativo y al Poder Judicial de un país (N. del T.). 
Sin embargo, concluir que el nombramiento o la designación de una norma como un "principio de derecho internacional", implica una naturaleza de carácter obligatorio, es algo prematuro, ya que tal designación no define su fuerza legal. ${ }^{26}$ Debido a su más general y fundamental carácter, los "principios de derecho internacional" tienen un significado más amplio y llevan a una variedad de aplicaciones y ejecuciones que difieren de una norma jurídica que define obligaciones o cargas y derechos de manera clara. ${ }^{27}$ Las "prácticas del Estado" no producen el mismo efecto sea que las normas sean aplicables o sea que no; las "prácticas del Estado" pueden explicar una argumentación que no necesariamente concluya en una sentencia; ${ }^{28}$ las "prácticas del Estado" pueden ser consideradas normas respecto de las cuales existe como una aspiración, es decir, como un deber ser aunque aquello no sea la actual existencia de normas jurídicas por cuanto ellas no se encuentran vigentes en un lugar y tiempo determinado. También pueden ser normas que ayuden en el desarrollo y aplicación de otras normas jurídicas que puedan servir como guías a las acciones de los Estados. ${ }^{29}$ Aunque es necesario dejar constancia que la mayoría de las "prácticas del Estado" deben sufrir un proceso de transformación que las convierta en normas jurídicas, ${ }^{30}$ esto no quiere indicar que las mismas no puedan ser aplicadas directamente. La última posibilidad (aplicación específica) puede ocurrir en caso de que el gobierno de un país lo determine en su proceso de decisión (por ejemplo, la aplicación del "principio de precaución" en la "crisis de la dioxina" en Bélgica en 1999) o en la sentencia de una corte en un caso non liquet. ${ }^{31}$

26 Hafner, G., "Commentary", en Lang, W. et al. (eds.) Environmental Protection and International Law, Londres, Graham y Trotman, 1991, p. 23.

27 Mosler, H., op. cit., nota 12, p. 73.

28 Fitzmaurice, G., "The General Principles of International Law, Considered from Standpoint of the Rule of Law", 95 Recueil des Cours de l'Académie de Droit International (RCADI), t. II, 1957, p. 7; Hoof, G. J. H. van, op. cit., nota 2, pp. 148 y 149, citado por R. Dworkin y Bin Cheng.

29 Dijk, P. van, "Normative Force and effectiveness of International Norms", 30 GYIL, 1987, pp. 14 y 15.

30 Virally, M., "Le role des 'principes' dans le dévelopment du droit international", Recueil d'etudes de droit international en hommage á Paul Guggenheim, Géneve, 1968, pp. 531-554 (esp. 533).

31 Véase para el concepto de non liquet expresado en las sentencias de la Corte Internacional de Justicia: Thirlway, H., "The Law and Procedure of the International Court of Justice", 60 BYIL, 1989, pp. 77-84; Desai, B., "Non Liquet and the ICJ Advi- 


\section{HACIA LA CODIFICACIÓN GLOBAL DE LOS "PRINCIPIOS DE DERECHOS DEL MEDIO AMBIENTE”}

La primera codificación universal de "práctica del Estado del medio ambiente" tuvo lugar en la Conferencia de Naciones Unidas sobre el Ambiente Humano (Estocolmo, junio de 1972), cuando 113 Estados adoptaron la denominada Declaración de Estocolmo y un plan de acción. El objetivo de la Declaración de Estocolmo fue inspirar a los gobiernos a preservar y mejorar el medio ambiente humano. Dicha declaración contiene 26 principios, sólo algunos han sido expresados de una manera obligatoria. Además, la declaración no puede ser considerada como un documento de carácter jurídico prima facie que oblige a Estados. El principio 2 de la declaración es una primera referencia a lo que se ha convertido posteriormente el "principio de desarrollo sostenible": "Los recursos naturales de la Tierra incluyen el aire, el agua, la tierra, la flora y la fauna y especialmente los ejemplos representativos de los ecosistemas naturales deben ser salvaguardados para el beneficio de las presentes y futuras generaciones a través de planificación cuidadosa o administración, como sea apropiado".

El principio 21 puede ser considerado como una nueva declaración de derecho internacional ${ }^{32}$ cuando a la fecha de su adopción indicó:

Los Estados tienen de acuerdo con la Carta de las Naciones Unidas y los principios de derecho internacional, el derecho soberano para explotar sus propios recursos a fin de perseguir sus propias políticas ambientales y la responsabilidad para asegurar las actividades en su jurisdicción o que el control no cause daño al medio ambiente o a otros Estados o en áreas más allá de los límites de la jurisdicción nacional.*

sory Opinion on the legality of the Treat of the use of Nuclear Weapons: Some Reflections", Indiana Journal of International Law, 1997, pp. 201-318.

32 Por ejemplo: Trail Smelter Arbitration (US vs. Canada), III United Nations Reports of International Arbitral Awards (UNRIAA), 1949, p. 1905, y Lake Lanoux Case (Spain vs. France), XII UNRIAA, 1957, p. 301.

* Todas las traducciones a los diferentes principios, contenidas en la "Declaración de Río sobre el Medio Ambiente y el Desarrollo, 1992" que el lector puede encontrar en este texto siguen la versión oficial del Programa de Naciones Unidas para el Medio Ambiente, Oficina Regional para América Latina, véase http://www.rolac.unep.mx/ docamb/esp/dr1992.htm (14-10-04) (N. del T.). 
No se ha podido alcanzar acuerdo alguno para incluir los "principios de notificación y consulta" en el caso de riesgos transfronterizos de actividades propuestas, ${ }^{33}$ lo que después ha sido llamado el "procedimiento de impacto ambiental de carácter transfronterizo".

El principio número 7, relacionado con la definición de contaminación marina, ha sido elaborado en detalle en la parte XII de la Convención sobre Derecho del Mar de las Naciones Unidas (1982). ${ }^{34}$ De acuerdo al principio 7: "Los Estados deben tomar todas las medidas posibles para prevenir la contaminación de los mares por substancias que pueden crear daños a la salud humana, dañar recursos vivos y vida marina, dañar servicios o interferir con otros usos legítimos del océano".

Veinte años después de Estocolmo, las Naciones Unidas organizó otra conferencia en esta área, la Conferencia de Naciones Unidas sobre Ambiente y Desarrollo (UNCED) que tuvo lugar en junio de 1992 en Río de Janeiro. Al final de ésta, 176 Estados adoptaron la denominada "Declaración de Río", por consenso. 35 También, la conferencia adoptó un plan de acción en la "Agenda 21", asimismo la Convención sobre Diversidad Biológica, la Convención sobre Cambio Climático y aprobó por consenso la Declaración sobre Principios Forestales. ${ }^{36}$ En diciembre de 1992, la resolución número 47/191 de la Asamblea General de Naciones Unidas estableció la Comisión de Desarrollo Sustentable de Naciones Unidas. ${ }^{37}$ El trabajo de esta nueva institución es recolectar datos sobre actividades ambientales y de desarrollo y, a su vez, controlar la implementación de la "Declaración de Río" y la "Agenda 21" a través de los Planes de Acción Nacional de los países participantes. La resolución 28/190 de la Asamblea General de Naciones Unidas (1993) impulsa a los

33 Birnie, P. W. y Boyle, A., Basic Documents on International Law and the Environment, Oxford, Clarendon Press, 1995, p. 1.

34 Véase supra nota 19.

35 Declaración de Río sobre Medio Ambiente y Desarrollo, Río de Janeiro, 13 de junio de 1992, 31 ILM, 1992, p. 876.

36 Convención sobre Diversidad Biológica, Río de Janeiro, 5 de junio 1992, 31 ILM, 1992, p. 818; Convención Marco sobre Cambio Climático, Río de Janeiro, Nueva York, 9 mayo de 1992, 31 ILM, 1992, p. 849; Declaración Autoritativa de Obligación No Jurídica acerca de Principios para el Consenso Global acerca de la Administración, Conservación y Desarrollo Sostenible de todos los Tipos de Bosques, 31 ILM, 1992, p. 881; Robinson, N. A. (ed.), Agenda 21: Earth's Action Plan, Nueva York, Oceana Publications, 1993.

3732 ILM, 1993, p. 254. 
gobiernos a promover la diseminación de los principios de la "Declaración de Río" en el sector público y privado, y solicita a las Naciones Unidas incorporar los principios en los programas y procesos del sistema de Naciones Unidas. ${ }^{38}$

Aunque la "Declaración de Río" no es formalmente obligatoria y debe considerarse como un instrumento de Soft Law, la adopción por consenso y el carácter normativo de las palabras usadas (por ejemplo, "debe" y "debería") entrega a los nuevos principios de la declaración un estatus autoritativo para un desarrollo posterior como principios jurídicos. En la "Declaración de Río", el contenido de los principios, previamente existente, ha sido modificado y reafirmado (por ejemplo, principio $2)^{39}$ y se han introducido nuevos "principios de derecho ambiental".

Los "Principios de Río" son inter alia la Participación pública y el acceso a la información ambiental (principio 10), la Prevención contra la reubicación y transferencia de actividades dañinas y substancias dañinas a otros Estados (principio 14), el Enfoque preventivo (principio 15), el Principio del que contamina paga (principio 16), la Evaluación del impacto ambiental en el ámbito nacional (principio 17), la Notificación de emergencias (principio 18) y la Previa notificación y consulta en el evento de un adverso y dañino efecto al medio ambiente de otros Estados (principio 19).

Excepto por el Principio de responsabilidad común pero diferenciada (principio 7), ${ }^{40}$ la mayoría de esos principios no eran realmente nuevos. Incluso el Principio de desarrollo sustentable (principio 3$)^{41}$ tiene sus raíces en el principio 2 de la Declaración de Estocolmo, limitado al contexto medio ambiental. En el periodo anterior a la Declaración de Río de Janeiro, todos los "principios de derecho ambiental" fueron aceptados en

38 Birnie, P. W. y Boyle, A., op. cit., nota 33, 1995, p. 9.

39 Principio 2, que es el principio 21 de la Declaración de Estocolmo, modificado por la referencia al desarrollo de políticas estatales en conjunto a las políticas ambientales.

40 "En vista de las diferentes contribuciones a la degradación ambiental, global, los estados tienen responsabilidades comunes pero diferenciadas. Los países desarrollados reconocen la responsabilidad que tienen en la búsqueda internacional del desarrollo sustentable, en virtud de las presiones que sus sociedades imponen al medio ambiente global y de la tecnología y recursos financieros de que disponen".

41 "El derecho al desarrollo debe ejercerse en forma tal que responda equitativamente a las necesidades de desarrollo y ambientales de las generaciones presentes y futuras" (principio 3, Declaración de Río). 
tratados regionales, recomendaciones de organizaciones regionales y en declaraciones ministeriales de carácter regional, aunque tienen diferente contenido y con aplicación restringida a ciertas regiones del mundo o a ciertas áreas del medio ambiente (por ejemplo, contaminación aérea o contaminación marítima). Algunos principios ambientales, como el referido a la Prevención de daños significativos ${ }^{42}$ al medio ambiente de otros Estados o daños significativos más allá de la jurisdicción nacional de los Estados y el Principio de cooperación entre Estados en casos de contaminación transfronteriza pueden encontrarse en las décadas de los sesenta y los setenta, cuando estos principios inspiraron a las partes a aceptar obligaciones específicas en convenciones regionales para la protección al "medio ambiente marino" y en convenciones regionales concernientes a la protección de "cursos de agua". ${ }^{43}$ El Principio del que contamina paga, introducido por la Organización para la Cooperación Económica y el Desarrollo en una recomendación de 1972,44 adquirió el estatus de un primer tratado ley de la Comunidad Económica Europea en el artículo 25 de la Acta Única Europea $(1986)^{45}$ y posteriormente, se ha incorporado como norma jurídica oligatoria en ciertos tratados regionales en el ámbito marítimo concluidos en 1992, tales como, la Convención de París para

42 Véase para determinar la diferencia entre calificación de daño apreciable/significativo/sustantivo: Sachariew, K., "The Definition of Thresholds of Tolerance for Transboundary Environmental Injury under International Law: Development and Present Status", XXXVII Netherlands International Law Review (NILR), 1990, pp. 193-206; Nollkaemper, A., The Legal Regime of Transboundary Pollution: Between Discretion and Constraint, Dordrecht-Boston-Londres, Martinus Nijhoff-Graham \& Trotman, 1993, pp. 35-40.

43 Véase Expert Group of the World Commission on Environment and Development, Environmental Protection and Sustainble Development, Legal Principles and Recommendations, Londres-Dordrecht-Boston, Graham-Trotman-Martinus Nijhoff, 1987, pp. 91 y 92; para ver una aproximación de lo que es la práctica estatal, McCaffrey, S., "Third Report on the Law of the Non-Navigational Uses of International Watercourses", Yearbook International Law Commission, 1987, t. II, pp. 43-58.

44 OECD, Recommendation on Guiding Principles concerning Environmental Policies, mayo de 1972, 11 ILM, 1972, p. 1172.

45 Ha sido incorporado el principio "El que contamina paga" entre otros en el artículo $130 \mathrm{R}$ del Tratado de la Comunidad Económica Europea. El principio "El que contamina paga" fue incorporado en Directivas de la Comunidad Económica Europea que fueron tempranas, e. g. Dir 75/442/EEC. El artículo 130R, en su última sentencia (el factor de "integración" en política medioambiental), ha devenido posteriormente en el artículo 6 del tratado de la Comunidad Económica Europea (Amsterdam, 1997). 
la Protección del Medio Ambiente Marino del Atlántico Noreste y la Convención de Helsinki acerca de la Protección del Ambiente Marino del Área del Mar Báltico, llegando a ser una parte de una convención. ${ }^{46}$

El Principio 14 de la "Declaración de Río" (contra la reubicación y transferencia de actividades dañinas y sustancias dañinas a otros Estados) ha tenido su aplicación en parte en la Convención de Basilea para el Control Transfronterizo de Desechos Peligrosos y su Deposición (1989) y la Convención de Bamako acerca de la Prohibición de la Importación de Desechos Peligrosos en África y el Control de Movimientos Transfronterizos (1991). ${ }^{47} \mathrm{El}$ "enfoque precautorio" fue introducido explícitamente en la Declaración del Mar del Norte, aunque tal aproximación puede encontrarse de manera implícita en las resoluciones de Naciones Unidas y en algunas convenciones concluidas antes de ese periodo. ${ }^{48} \mathrm{En}$ la recomendación PARCOM89/1 de 22 de junio de 1989, el enfoque tomó la forma del Principio de acción precautoria y en la Convención de París para la Protección del Medio Ambiente Marino del Atlántico Nor-Este (1992) el enfoque se tornó el "principio precautorio" (artículo 2, párrafo 2, letra "a"). En la Convención Bamako el "enfoque precautorio" y el "principio precautorio" son usados en el mismo artículo 4, numero 3, letra "f". El Tratado de Maastricht (1992) incluyó el principio precautorio de los Principios Ambientales de la Comunidad Europea sin entregar definición del principio (artículo 130 "R”, párrafo 2).

46 Artículo 2 (2) (b), Convention for the Protection of the Marine Environment of the North East Atlantic, París, 22 de septiembre de 1992, 32 ILM, 1993, p. 1069; artículo 3 (4), Convention on the Protection of the Marine Environment of the Baltic Sea Area, Helsinki, 9 de abril de 1992, 8 IJMCL, 1993, p. 215; véase Sands, P., Principles of International Environmental Law I: Frameworks, Standards and Implementation, Manchester-Nueva York, Manchester University Press, 1995, p. 216.

47 Basel Convention, 22 de marzo de 1989, 28 ILM, 1989, p. 649; Bamako Convention, 29 de enero de 1991, 30 ILM, 1991, p. 773.

48 E.g. art. 11 (b), UNGA Resolution 7 (XXXVII), World Charter for Nature, 28 de octubre de 1982; véase Freestone, D., "The Precautionary Principle", en Churchill, R. R. e id. (eds.), International Law and Global Climate Change, Londres, Graham y Trotman, 1991, pp. 21-30; Hey, E., "The Precautionary Concept in Environmental Policy and Law: Institutionalising Caution", 4 Geo. Int'l. Envtl. L. Review, 1992, p. 311; Freestone D. y Hey, E., "Origins and Development of the Precautionary Principle", en id. (eds.), The Precautionary Principle and International Law: The Challenge of Implementation, The Hague, Kluwer, 1996, pp. 3-15. 
Durante la preparación de la Conferencia de Naciones Unidas para el Medio Ambiente y el Desarrollo en 1992, varias iniciativas regionales tuvieron lugar, lo cual resultó en nuevas convenciones regionales. La Convención sobre Evaluación del Impacto Ambiental en un Contexto Transfronterizo, concluida en Espoo el 25 de febrero de 1991, es la primera convención que define normas detalladas, procedimientos y prácticas para la evaluación del impacto ambiental transfronterizo. ${ }^{49}$ La Convención de los Efectos Transfronterizos de los Accidentes Industriales, concluido en Helsinki el 7 de marzo de 1992, es la primera convención que establece principios para la "prevención y la preparación de respuestas a los efectos de accidentes industriales y las actividades que envuelven substancias dañinas capaces de causar efectos transfronterizos". 50

El concepto de "desarrollo sostenible", como principio de derecho, es más problemático. Aunque algunos especialistas han argumentado que este concepto puede tener origen en las convenciones para proteger la naturaleza ${ }^{51}$ y recursos naturales, ${ }^{52}$ especialmente en el arbitraje Pacific

4930 ILM, 1991, p. 800. Esta convención se encuentra abierta para la firma de los países miembros de la Comisión Económica de Naciones Unidas para Europa y la Comunidad Europea, y fue inspirada en la Directiva de la Comunidad Económica 85/337/CEE sobre Evaluación del Impacto Ambiental.

5031 ILM, 1992, p. 1330.

51 Véase "Legalidad del uso de armas nucleares", Opinión de disenso del juez señor Weeramantry, ICJ Reports, 1996, pp. 455 y 456.

52 Phillipe Sands concluye que: "Donde él (el "desarrollo sostenible") parece estar unido al menos a cuatro objetivos separados pero relacionados que, considerados en su conjunto, pueden comprometer los elementos jurídicos del concepto de "desarrollo sostenible"... Primero, como ha sido invocado en algunos acuerdos, éste se refiere al compromiso para preservar recursos naturales para el beneficio de las generaciones presentes y futuras. Segundo, en otros acuerdos "desarrollo sostenible" se refiere a los estándares para la explotación de recursos naturales basado en el uso o en la siega... Tercero, otros tratados requieren un uso equitativo de los recursos naturales, sugiriendo que el uso por cualquier Estado debe tomar en consideración las necesidades de otros Estados y de las personas. Una cuarta categoría de tratados requiere que las consideraciones ambientales deben ser integradas en planes, programas o proyectos económicos y de otro planes de desarrollo y que estas necesidades de desarrollo deben ser tomadas en consideración al aplicar objetivos medioambientales", Sands, Ph., "Environmental Protection in the Twenty-first Century: Sustainble Development and International Law", en Vig, N. J. y Axelrod, R. S. (eds.), The Global Environment. Institutions, Law and Policy, Londres, Earthscan, 1999, pp. 128 y 129. 
Fur Seal Arbitration (1893), ${ }^{53}$ hay todavía alguna duda acerca del estatus de desarrollo sostenible como "principio de derecho internacional" y su aplicación en la práctica estatal. La Corte Internacional de Justicia en el caso Gabcikivi-Nagymaros (1997) referido al "concepto" de "desarrollo sostenible", en vez de expresar una necesidad para reconciliar desarrollo económico como "principio de derecho internacional", lo expresa como un concepto legal o como un concepto de derecho internacional. ${ }^{54}$ El juez Weeramantry, en su opinión disidente a esta sentencia, argumenta que el Principio de desarrollo sostenible es parte del derecho internacional moderno y de la práctica estatal. Para él es más que un concepto y debe ser considerado como un principio con valor normativo. ${ }^{55}$

Sin embargo, la introducción y la reiteración de los "principios de derecho ambiental" en la "Declaración de Río", en un instrumento globalmente aceptado, debe ser considerado como un principio de valor normativo, siendo esto algo novedoso. Esto significa que la Organización de Naciones Unidas no puede ignorar estos principios en su proceso de toma de decisiones. Los "principios de derecho internacional" pueden, en los hechos, convertirse en "principios generales", en el sentido que ellos son potencialmente aplicables a todos los miembros de la comunidad internacional a través de todas las posibles actividades que ellos quieran llevar a cabo o permitir que se lleven a cabo y que ella enfrente todos los aspectos de protección del medio ambiente. Aunque los "Principios de Río" debe ser considerados como una norma jurídica no-obligatoria, la mayoría de ellas han sido introducidas en nuevos tratados internacionales y deben ser parte de derechos de los tratados. Como estos principios deben estar en balance con otros principios, hay una posibilidad para un potencial conflicto.

53 Sands, Ph., "International Law in the Field of Sustainble Development: Emerging Legal Principles", en Lang, W. (ed.), Sustainble Development and International Law, Londres-Dordrecht, Graham y Trotman, 1995, p. 58; Vig, N. J. y Axelrod, R. S. (eds.), op. cit., nota anterior, p. 127.

54 Gabcikovo-Nagymaros Project (Hungary-Slovakia), Judgement, ICJ Reports, 1997, p. 78, párr. 140.

55 Opinión separada del vice-presidente señor Weeramantry, ICJ Reports, 1997, p. 85 , párr. 92 . 


\section{PRINCIPIOS DE DERECHO AMBIENTAL Y EL DERECHO DEL MAR}

Los más importantes principios y normas jurídicas concernientes al uso de los océanos y mares han sido codificados en la Convención de Naciones Unidas sobre Derecho del Mar (1982), que pueden ser considerados como la Constitución de los océanos. ${ }^{56}$ Ha tomado a los negociadores cerca de catorce años poder obtener un texto que exprese los compromisos adoptados, y tomó otros doce años, antes que la convención entrara en vigor el 16 de noviembre de 1994, después de que un Acuerdo Relativo a la Aplicación de la Parte XI de la Convención sobre el Derecho del Mar de Naciones Unidas fuere alcanzado para poder conseguir regular las partes del fondo marino. ${ }^{57}$ Ahora hay 137 Estados partes de la convención, y 103 Estados son partes del acuerdo. Entre 1982 y 1994, algunos principios y normas en la Convención sobre Derecho del Mar de Naciones Unidas han adquirido un estatus de costumbre internacional, por ejemplo, el límite territorial de 12 millas náuticas y el derecho de los Estados ribereños para proclamar una zona económica exclusiva de 200 millas náuticas. La parte número XII acerca de la Protección y Preservación del Medio Ambiente Marino es uno de los más importantes intentos globales para dar un balance de los derechos de explotación de los Estados y sus obligaciones para proteger el medio ambiente marino.

De acuerdo al artículo 194, párrafo 2:

Los Estados tomarán todas las medidas necesarias para garantizar que las actividades bajo su jurisdicción o control se realicen de forma tal que no causen perjuicios por contaminación a otros Estados y su medio ambiente, y que la contaminación causada por incidentes o actividades bajo su jurisdicción o control no se extienda más allá de las zonas donde ejercen derechos de soberanía de conformidad con esta convención.

Usar la palabra "Estados" en vez de "partes" (artículo 194, párrafo 2), es una obligación general para todos los Estados y no es restringido a las partes en la Convención de Derecho del Mar. Para la Corte Inter-

56 Idem.

57 Acuerdo Relativo a la Implementación de la Parte XI de la Convención de Naciones Unidas sobre el Derecho del Mar del 10 de diciembre de 1982, Nueva York, 28 de julio de 1982, 33 ILM, 1994, p. 1309. En vigencia desde el 28 de julio de 1996. 
nacional de Justicia, en su opinión consultiva denominada caso "Nuclear Weapons" (1996), esta obligación general se ha convertido en parte del haber del derecho internacional relacionado con el medio ambiente. ${ }^{58}$ Sin embargo, enfrentado este principio contra otros principios de derecho internacional como el derecho de autodefensa, la Corte Internacional de Justicia fue de la opinión que esta obligación ambiental no tiene pretensiones de ser una obligación de freno o contención durante el conflicto militar. Al recordar el principio 24 de la "Declaración de Río", 59 la corte ha sido de la opinión que: 60 "Los Estados deben tomar consideraciones medioambientales cuando evalúan lo que es necesario y proporcional en la persecución de objetivos militares legítimos. El respeto por el medio ambiente es uno de los elementos que van a evaluar cuando una acción es de conformidad con los principios de necesidad y proporcionalidad".

Los Estados tienen una clara obligación ("debe") para proteger y preservar el medio ambiente marino (artículo 192), pero también el derecho a explotar sus recursos naturales para perseguir sus propias políticas ambientales (artículo 193). De acuerdo al artículo 193: "Los Estados tienen el derecho soberano de explotar sus recursos naturales con arreglo a su política en materia de medio ambiente y de conformidad con su obligación de proteger y preservar el medio marino". Nuevamente, las obligaciones y los derechos no están limitados a las partes contratantes, pero son aplicables a todos los Estados y a todo el medio ambiente marino. Estos dos "principios de derecho internacional", la obligación de proteger el medio ambiente marino y el derecho de los Estados para explotar sus recursos naturales, la última como un corolario del derecho proveniente de la soberanía permanente y los derechos al desarrollo de los

58 Opinón Consultiva acerca de la Legalidad de la Amenaza o el Uso de Armas Nucleares a petición de la Asamblea General de Naciones Unidas, ICJ Reports, 1996, párr. 29.

59 "Las acciones de guerra son inherentemente destructivas del desarrollo sostenible. Los Estados deben, por lo tanto, respetar el derecho internacional proveyendo protección del medio ambiente en tiempos de conflicto armado y cooperación en el caso de un desarrollo ulterior, si es necesario" (principio 24, Declaración de Río de Janeiro sobre Medio Ambiente y Desarrollo).

60 Estatuto 58, p. 30. 
Estados, al balancear intereses globales con intereses nacionales. ${ }^{61}$ Las raíces de artículo 193 se hallan en el "principio 21" de la Declaración de Estocolmo y la posición de los países en desarrollo. Políticas medioambientales de Estados desarrollados no deben debilitar las posiciones comerciales y de desarrollo de países en desarrollo. Referencias a las "políticas medioambientales" de los Estados individuales introducen un “doble estándar", un estricto estándar medioambiental para los países desarrollados y otros más estrictos para países en desarrollo. ${ }^{62}$ Esta posición está reflejada en el "principio 11 de la Declaración de Estocolmo": ${ }^{3}$

Las políticas ambientales de todos los Estados deberían estar encaminadas a aumentar el potencial de crecimiento actual o futuro de los países en desarrollo y no deberían coartar ese potencial, no obstaculizar el logro de mejores condiciones de vida para todos. Los Estados y las organizaciones internacionales deberían tomar las disposiciones pertinentes con miras de llegar a un acuerdo para hacer frente a las consecuencias económicas que pudieran resultar, en los planos nacional e internacional, de la aplicación de medidas ambientales.

Este doble estándar ha sido introducido en el artículo dos de la Convención de Londres sobre Descarga (1972) y más claramente en el ar-

61 Véase también la Resolución de la Asamblea General de Naciones Unidas 3133 (XXVIII) sobre Protección del Medio Ambiente Marino (13 de diciembre de 1973), 13 ILM, 1974, p. 234; Resolución de la Asamblea General de Naciones Unidas 3281 (XXXIX), Carta de Derechos y Obligaciones Económicas de los Estados (12 de diciembre de 1974), 14 ILM, 1975, 254 rn, pp. 206-261; Resolución de la Asamblea General de Naciones Unidas 3016 (XXVII) La Soberanía Permanente de los Países Subdesarrollados sobre sus Recursos Naturales (18 de diciembre de 1972), 13 ILM, 1974, p. 238; Resolución de la Asamblea General de Naciones Unidas 2894 (XXVI) Desarrollo y Medio Ambiente (20 de diciembre de 1971), 11 ILM, 1972, p. 422; principio 21, Declaración de Estocolmo; principio 2, Declaración de Río; Schrijver, N., Sovereignty over Natural Resources. Balancing Rights and Duties, Cambridge, Cambridge University Press, 1997, pp. 35-142.

62 Hakapaa, K., Marine Pollution in International Law, Helsinki, Suomalainen Tiedekatemia, 1998, pp. 60-62.

63 Véase también principio 11, "Declaración de Río": "Los estados deben promulgar legislación ambiental efectiva. Estándares ambientales, objetivos y prioridades de administración deben reflejar el contexto al cual ellos son aplicables. Estándares son aplicables por algunos países pueden ser inapropriados y de consecuencias económicas y sociales no buscadas". 
tículo 194 párrafo 1 de la Convención sobre Derecho del Mar de Naciones Unidas: ${ }^{64}$

Los Estados tomarán, individual o conjuntamente según proceda, todas las medidas compatibles con esta convención que sean necesarias para prevenir, reducir y controlar la contaminación del medio marino procedente de cualquier fuente, utilizando a estos efectos los medios más viables de que dispongan y en la medida de sus posibilidades, y se esforzarán por armonizar sus políticas al respecto.

La referencia a las mejores maneras prácticas y las capacidades aparece después, en el artículo 3, párrafo 1, de la Convención sobre Cambio Climático, el Principio de la responsabilidad común pero diferenciada para tomar en consideración las necesidades especiales de países en desarrollo. ${ }^{65}$ En el Protocolo de Kyoto (1997) de la Convención sobre Cambio Climático, los países desarrollados aceptaron cuantificar la reducción de emisiones de seis gases de greenhouse cuando los países desarrollados no poseen tal obligación. ${ }^{66}$ El Principio de la responsabilidad común pero diferenciada de los Estados implica que aunque todos los Estados tienen responsabilidad de proteger a la Tierra contra los peligros medioambientales globales, los países desarrollados tienen una mayor responsabilidad por su gran contribución a los problemas ambientales y deben tomar medidas más exigentes. El principio lleva a diferentes esfuerzos para los Estados de proteger el medio ambiente. ${ }^{67}$ Más aún, bajo la Convención sobre Derecho del Mar de Naciones Unidas, a los Estados en vías de desarrollo les ha sido garantizado un tratamiento preferencial por las organizaciones internacionales en a) La repartición o ubicación de los fondos apropiados y de la asistencia técnica; y b) La utilización de sus servicios especializados (artículo 203). Los Estados deben garantizar la asistencia científica, educacional, técnica y otro tipo de asistencia para Estados en desarrollo, para inter alia disminuir los efectos que grandes

64 Véase Hakapaa, K., op. cit., nota 62, pp. 63-65.

65 Véase también principio 7, "Declaración de Río" y "Preámbulo" de la Convención sobre Diversidad Biológica.

66 Protocolo a la Convención de Naciones Unidas para la Convención Marco sobre el Cambio Climático, Kyoto, 10 de diciembre de 1997, 37 ILM, 1998, p. 22.

67 Sands, Ph., "International...", en Lang, W. (ed.), op. cit., nota 53, pp. 63 у 64; Sands, Ph., "Environmental...", en Vig, N. J. y Axelrod, R. S., op. cit., nota 52, p. 108. 
incidentes han causado, como polución seria, y en la preparación de la evaluación del impacto ambiental (artículo 202).

Para proteger al medio ambiente marino e implementar el artículo 192 y el artículo 194 (incisos primero y segundo), las medidas deben ser tomadas para prevenir, reducir y controlar la contaminación de los mares por cualquier causa o fuente - fuentes terrestres, navíos, instalaciones en el mar- (Principio de la prevención). De acuerdo con la Convención del Derecho del Mar de Naciones Unidas, los Estados "deben" adoptar leyes y regulaciones, y cooperar a un ámbito global y regional para alcanzar la armonización del establecimiento de las normas jurídicas, estándares, prácticas recomendadas y procedimientos para prevenir, reducir y controlar todas las grandes fuentes de contaminación marítima como la contaminación de fuente terrestre (artículo 207), contaminación cuya fuente se encuentra en el fondo marino (artículo 208), la descarga en el mar (artículo 210), contaminación de navíos (artículo 211), y contaminación atmosférica (artículo 212). Cuando los Estados se dan cuenta del inminente daño o actual daño al medio ambiente marítimo por la contaminación, ellos deben notificar inmediatamente a otros Estados que podrían ser probablemente dañados (artículo 198). Especial atención debe prestarse a proteger y preservar los ecosistemas raros y frágiles, así como el hábitat de especies agotadas, amenazadas o en peligro (artículo 194, inciso quinto). Varias convenciones que han creado áreas protegidas para la protección de hábitats de las especies han sido concluidas antes que la Convención sobre el Derecho del Mar de Naciones Unidas fuese abierta para la firma. ${ }^{68}$

Tres artículos en la Convención sobre el Derecho del Mar de Naciones Unidas merecen atención especial, porque al momento en que la convención fue abierta para la firma, estos artículos fueron considerados legítimamente como innovaciones.

68 Convención de Washington sobre Protección de la Naturaleza y Protección de la Vida Silvestre en el Hemisferio Occidental; Convención de París sobre la Protección de los Pájaros de 1950; Convención Africana para la Conservación de la Naturaleza y de los Recursos Naturales de 1968; Convención RAMSAR para la Protección de Humedales de Importancia Internacional, especialmente en los hábitat de pájaros acuáticos de 1971; Convención de Londres para la Conservación de Ballenas Antárticas de 1972; Convención de París para la Protección del Legado Cultural y Natural; Convención Apia para la Conservación de la Naturaleza en el Pacífico Sur; Convención de Berna para la Protección de Animales Migratorios de 1979. 
El artículo 195 introduce el deber de no transferir, directa o indirectamente, daño o peligro desde un área a la otra o transformar un tipo de contaminación en otra. Los Estados tienen una clara obligación acá, ellos "actuarán de manera que no transfiera". Esta obligación se ha repetido en el artículo 3, inciso tercero, del Protocolo de la Convención de Londres sobre Vertido. ${ }^{69}$ Esto significa, por ejemplo, que las medidas para prevenir el vertido de desechos industriales en el mar (que se encuentra prohibido inter alia en el artículo cuatro del Protocolo a la Convención de Londres sobre Vertido) no puede resultar en contaminación de un aérea adicional; o la prohibición de vertido contaminante en el mar territorial puede no resultar en vertido en alta mar.

Una segunda innovación es el artículo 196 acerca de la introducción de extraños o nuevas especies. Los Estados están obligados a tomar todas las medidas necesarias para prevenir, reducir y controlar la contaminación del medio ambiente marino que resulte del uso de tecnologías bajo su jurisdicción o control, o por la introducción accidental de especies extrañas o nuevas. La implementación de este artículo ha sido considerada muy seriamente por el gobierno belga en la Ley de Protección de Áreas Marinas bajo jurisdicción belga (1999). ${ }^{70}$ En esta ley, la introducción de especies extrañas requiere un permiso después de haberse probado que la introducción de tales especies no tendrá consecuencias negativas sobre la fauna y flora endémica (esto es, el Principio de precaución).

Una tercera innovación en derecho ambiental en la Convención sobre el Derecho del Mar ha sido la introducción de un proceso de evaluación del impacto ambiental para evaluar los potenciales efectos de actividades planificadas que pueden causar contaminación sustancial o cambios sustantivos y dañosos al medio ambiente marino (artículo 206). El artículo 206 puede ser considerado una obligación "soft" para los Estados, desde que una evaluación del impacto ambiental es requerida "cuando los Estados tienen un razonable sustento para creer" que esas actividades van a causar tales efectos. Además, una evaluación es obligatoria "sólo en caso que sea posible", y deja discrecionalidad para los Estados

69 Protocolo de 1972 de la Convención para la Prevención de la Contaminación Marina y de otras Materias Desechables, Londres, 7 de noviembre de 1996, 36 ILM, 1997, p. 1.

70 Véase supra nota 1; también Cliquet, A. y Maes, F., "The New Belgian Law on the Protection of the Marine Environment", I Journal of International Wildlife \& Policy, 1998, p. 105 (esp. 102). 
con el fin de usar o no la evaluación de impacto ambiental para actividades planificadas. La ley belga de 1999 requiere una evaluación del impacto ambiental para cada actividad en el mar, para lo cual el permiso gubernamental es requerido con la excepción de actividades de pesca (artículo 28 de la Ley de 1999).

La Convención sobre Derecho del Mar de Naciones Unidas no menciona el Principio precautorio, el Principio del que contamina paga o el Principio de desarrollo sostenible. ${ }^{71}$ Estos principios fueron incluidos después de que la convención concluyó. Sin embargo, la definición de contaminación marina en la Convención sobre el Derecho del Mar de Naciones Unidas cuando se usa la palabra "probablemente" no es un obstáculo para aplicar el Principio precautorio, aunque su aplicación es nombrada o definida que parece estar limitada a la introducción de sustancias y energía en el medio ambiente marino. Contaminación del medio ambiente marino significa (artículo 1, párrafo cuarto):

La introducción por el hombre, directa o indirectamente, de sustancias o de energía en el medio marino incluidos los estuarios, que produzca o pueda producir efectos nocivos tales como daños a los recursos vivos y a la vida marina, peligros para la salud humana, obstaculización de las actividades marítimas, incluidos la pesca y otros usos legítimos del mar, deterioro de la calidad del agua del mar para su utilización y menoscabo de los lugares de esparcimiento.

Más allá de las medidas para ser tomadas por Estados individuales, los Estados han aceptado la obligación de cooperar a un nivel global y regional para implementar la parte XII de la convención. ${ }^{72}$ El Principio

71 Véase también las medidas provisionales ordenadas en el caso SBT por el Tribunal Internacional sobre Derecho del Mar, donde éstas [medidas] no se encuentran basadas en el principio precautorio, a pesar de la solicitud para que se le diera tal efecto: Southern Bluefin Tuna Cases (New Zealand-Japan, Australia-Japan), Order, 38 ILM 1999, p. 1624. En su opinión "separada", el juez Laing argumenta que estas medidas provisorias ordenadas por el tribunal se encuentran fundadas en la "aproximación precautoria": 38 ILM, p. 1642, párr. 19.

72 En particular, artículos 197, 199, 200, 202, 207 (4), 208 (5), 209 (1), 210 (4), 212 (3), 226 (2), 235 (3) y 242(2), Convención sobre el Derecho del Mar; véase Pinto, M. C. W., "The Duty of Co-Operation and the United Nations Convention on the Law of the Sea”, en Bos, A. y Siblesz, H. (eds)., Realism in Law Making. Essays on International Law in Honour of W. Riphagen, Dordrecht, Martinus Nijhoff, 1986, p. 135. 
de la cooperación entre Estados para proteger el medio ambiente se encuentra expresado en casi todos los tratados ambientales, en resoluciones y decisiones de organizaciones internacionales, en el Principio 27 de la "Declaración de Estocolmo" y en el Principio 7 de la "Declaración de Río". El Principio de cooperación para proteger el medio ambiente es una obligación de carácter procedimental y actualmente ha sido considerada como parte de la costumbre internacional. ${ }^{73}$ En el caso de contaminación por barcos, las partes a la Convención sobre el Derecho del Mar de Naciones Unidas han aceptado la obligación de cooperar entre ellas a un nivel global bajo el ala de la Organización Marítima Internacional de las Naciones Unidas, sin excluir la cooperación regional. ${ }^{74}$ En Europa existe una norma jurídica para la cooperación regional concerniente a planes de contingencia para responder a incidentes de contaminación en el mar, y la organización de la vigilancia aérea para detectar la descarga de residuos en el mar que violan la ley (por ejemplo, Acuerdo de Bonn para la Cooperación en Materia de Contaminación del Mar del Norte $)^{75}$ y la cooperación regional del control portuario (Memorando de Entendimiento de París). ${ }^{76}$ En el ámbito global hay acuerdos en torno a vertidos de desechos al mar (La Convención de Londres sobre Vertidos de 1972), ${ }^{77}$ la protección del medio ambiente durante operaciones de salvamento (Convención de Salvamento de 1978) ${ }^{78}$ y la Convención de Con-

73 Francioni, F., "International Co-operation for the Protection of te Environment: The procedural Dimension", en Lang, W. et al., (eds.), "Environmental...", cit., nota 26, p. 231.

74 Véase, en lo que se refiere al proceso de creación de la norma jurídica en OMI: Birnie, P., "The Status of Environmental 'Soft-Law': Trends and Examples with Special Focus on IMO Norms", en Ringbom, H., Competing norms in the Law of Marine Environmental Protection, Londres-The Hague-Boston, Kluwer Law International, 1997, p. 31.

75 Acuerdo para la Cooperación en Materia de Contaminación en el Mar del Norte por Petróleo y otras Substancias Dañinas, Bonn, 13 de septiembre de 1983, OJ L 188/9, 16 de julio de 1984.

76 Memorandum de Entendimiento Acerca del Control sobre Puertos Estatales, París, 26 de enero de 1982, 21 ILM, 1982, p. 1; véase también la Directiva del Consejo 95/21/EC de 19 de junio de 1995 concerniente al control estatal de los puertos, OJ L 157/1, 7 de julio de 1995 .

77 Convención para el Descarga de Desechos al Mar, Londres, 13 de noviembre de 1972, 11 ILM, 1972, p. 1294.

78 Convención Internacional de Salvamento, Londres, 28 de abril de 1989, Lloyd's Maritime and Commercial Law Quarterly, 1990, p. 54. 
taminación por Vertido de Hidrocarburo, Preparación, Respuesta y Cooperación (OPRC). ${ }^{79}$ Sin embargo, no hay un acuerdo global para proteger los océanos contra la polución, cuyo origen se encuentra en el territorio terrestre que es la fuente de más del 70\% de la contaminación vertida en los mares y océanos.

\section{LA PROTECCIÓN DEL MEDIO AMBIENTE EN EUROPA Y EN BÉLGICA}

En el oeste europeo, la cooperación regional para proteger el medio ambiente marino ha sido una realidad aun antes de la existencia de la Convención sobre el Derecho del Mar de Naciones Unidas antes que ésta fuere abierta para la firma. Varios acuerdos de carácter regional se concluyeron durante la década de los años setenta a ochenta para prevenir, controlar y reducir la contaminación marina en el Mar Báltico, ${ }^{80}$ el Atlántico Noreste ${ }^{81}$ y el Mar Mediterráneo. ${ }^{82}$ Otras convenciones relativas al medio marino en el ámbito internacional han sido inspiradas por el Programa Regional Marino del Programa de Naciones Unidas, que fuere iniciado en 1974, e incluye 14 Estados con costa. ${ }^{83}$ Las convenciones para proteger el Mar Báltico y el Mar Atlántico Noreste fueron sustancialmente revisadas en 1992, y son las primeras convenciones que explícitamente introducen principios medioambientales entre las obligaciones que se encuentran en los textos de las convenciones. Las partes contratantes a la Convención de París de 1992 poseen la obligación de prevenir

79 Convención Internacional para la Preparación de la Contaminación por Combustible, Respuesta y Cooperación, Londres, 20 de noviembre de 1989, 30 ILM, 1991.

80 Convención para la Protección del Medio Ambiente Marino del Mar Báltico, Helsinki, 22 de marzo de 1974, 13 ILM, 1974, p. 546.

81 Convención para la Prevención de la Polución Marina por Descarga desde los Barcos y Aviones, Oslo, 15 de febrero de 1972, 11 ILM, 1972, p. 262; Convención para la Prevención de la Contaminción Marina desde Fuentes Situadas en Tierra Firme, París, 4 de junio de 1974, 13 ILM 1974, p. 352.

82 Convención para la Protección del Mar Mediterráneo contra la Contaminación, Barcelona, 16 de febrero de 1976, 15 ILM, 1976, p. 290.

83 De acuerdo a la Resolución 2997 (XXVII) de la Asamblea General de Naciones Unidas, el Programa de Naciones Unidas para el Medio Ambiente (PNUMA) fue establecido como lugar de reunión (focal point en el original) para los actos ambientales y coordinación [de estos actos] dentro del sistema de Naciones Unidas. Véase para los detalles: http://www.unep.org/unep/program/natres/water/regseas/. 
y eliminar contaminación $\mathrm{y}$, del mismo modo, se encuentran sometidos a la obligación del área que la convención ha fijado contra efectos adversos propios de la actividad humana y, cuando sea posible, restaurar áreas marinas que han sido afectadas negativamente (artículo 2, letra "a", párrafo primero). Para dar efecto a los últimos, los ministros de medio ambiente aceptaron un nuevo anexo, el número V, a la Convención de París de 1992 durante la reunión ministerial en Sintra del 22 al 23 de julio de 1998. El anexo número V repite el objetivo de restauración y comisiona a la Comisión (OSPAR Commission), inter alia, para desarrollar medios, consistentes con el derecho internacional, con el fin de establecer medidas de carácter protector, medidas de conservación y restauración o medidas de precaución para sitios o áreas específicas o para particulares especies o hábitats excluyendo a las zonas de pesca. ${ }^{84}$ El Principio de la restauración ecológica ha sido mencionado en la Convención de Helsinki de 1992 (artículo 3, párrafo 1).

En las dos convenciones, las partes tienen que aplicar el Principio de precaución: 85

El Principio de precaución, en cuya virtud las medidas preventivas habrán de ser tomadas cuando haya razones fundadas para considerar que substancias o energía introducida directa o indirectamente en el medio ambiente marino puede traer daño a la salud humana, dañar los recursos marinos vivos y los ecosistemas marinos, dañar amenidades, o interferir con otros usos legítimos del mar aun cuando no exista evidencia concluyente de una relación causal entre el origen de los ingresos y los efectos.

Las dos convenciones usan casi idénticas definiciones acerca del Principio de precaución, dado que Suecia, Dinamarca, Alemania y Finlandia negociaron la Convención de París de 1992 y la Convención de Helsinki durante el mismo periodo. Estas definiciones son diferentes de las definiciones de Río (principio 15):

84 Artículo 3 (1) (b) (ii), Annexo V sobre la Protección y Conservación de los Ecosistemas y la Diversidad Biológica del Área Marina, 28 Environmental Policy and Law (EPL), 1998, p. 286.

85 Artículo 2,2 (a), Convención de París de 1992; véase también artículo 3 (2), 1992 de la Convención de Helsinki. 
A fin de proteger el medio ambiente, la aproximación precautoria debe ser aplicada de manera general por los Estados de acuerdo a sus capacidades. Donde haya riesgos de daños serios o irreversibles, falta de certeza científica absoluta no puede ser usada para posponer medidas relacionadas con costo-efectividad a fin de prevenir degradación ambiental.*

En la "Declaración de Río", al Principio de precaución se le llama Aproximación precautoria, y por tanto el aplicar el principio posee un poder mayor que en las convenciones de París de 1992 y de Helsinki de 1992 en "razón a la referencia de daño serio e irreversible". ${ }^{86}$ Una vez que claramente el daño es irreversible, las medidas a tomar no difieren de las medidas preventivas como resultado de la aplicación del Principio de precaución en su sentido clásico o primigenio, desde que la calificación de "daño serio e irreversible" depende de una clara evaluación científica, que el Principio de precaución busca sobrepasar en parte. Además, "total seguridad científica" es muy rara y en la mayoría de los casos habrá una falta de seguridad científica absoluta, así que resulta mejor referirse a "evidencia no concluyente".

Es aquí en donde podemos explicar una definición diferente del Principio de precaución debido a que la "Declaración de Río" hace aplicable a todo el medio ambiente el Principio precautorio (agua, tierra, aire...) donde las convenciones de París y Helsinki se encuentran limitadas al medio ambiente marino. Sin embargo, la Convención de Barcelona para proteger el Mediterráneo, enmendada en 1995, sucede en el artículo 4, párrafo 3, letra "a" de la definición de la "Declaración de Río", y el "enfoque" es llamado "principio", en el Protocolo de 1996 a la Convención de Londres sobre Vertido. La definición es similar a la contenida en la Convención de París de 1992, y es, del mismo modo, llamada un "enfoque". En otras palabras, allí no hay siempre una diferencia inherente entre definiciones, dependiendo de si una definición se relaciona con el principio

* Todas las traducciones a los diferentes principios contenidas en "Declaración de Río sobre el Medio Ambiente y el Desarrollo, 1992" que el lector puede encontrar en este texto, siguen la versión oficial del Programa de Naciones Unidas para el Medio Ambiente, Oficina Regional para América Latina, véase http://www.rolac.unep.mx/ docamb/esp/dr1992.htm (14-10-04) (N. del T.).

86 Véase también para un análisis, De Sadeleer, N., pp. 172-184. 
precautorio o el enfoque precautorio. ${ }^{87}$ En la ley francesa de 1995, el Principio precautorio no está limitado a la protección de los mares, y significa: 88 "Independiente de la ausencia de certeza como de los conocimientos científicos y técnicos del momento, no se podrá retrasar la adopción de medidas efectivas y proporcionales para prevenir un riesgo de daño grave e irreversible al medio ambiente a un costo económico aceptable".

La ley belga de 1999 para Proteger el medio ambiente marino sigue una definición de la Convención de París de 1992, incluyendo la introducción de materiales en el mar: ${ }^{9}$

El Principio de precaución significa que las medidas de prevención deben poseer motivos razonables de su inquietud de una contaminación de los espacios marinos aunque la existencia de una prueba concluyente de una línea causal entre la introducción de las substancias, de energías o de los materiales dentro de los espacios marinos y los efectos visibles (nuisibles).

El Principio precautorio ha inspirado al legislador belga a prohibir la introducción deliberada de organismos genéticamente modificados en el mar (artículo 11, párrafo 4). Toda persona que proponga la introducción de especies ajenas en el medio ambiente marino, debe probar que tal introducción carece de efectos sobre la flora y fauna endémica antes de que pueda serle otorgado un permiso. Dueños de barcos y operadores se encuentran obligados a remover barcos que se encuentran hundidos, y/o barcos de carga en el mar, sólo si existe potencial riesgo de contaminación que emana desde el mismo. "Derelictio" o el abandono de barcos que han naufragado o barcos de carga es sólo posible después de que un permiso ha sido garantizado basándose en una evaluación de impacto ambiental hecha por las personas que están proponiendo el abandono (artículo 75).

87 Véase para la diferenciación entre "principio" y "aproximación" acerca del principio precautorio, la opinión separada del juez Lang en el caso SBT: "adoptando una aproximación, en lugar de un principio, introduce apropiadamente un cierto grado de flexibilidad y pretende, aunque no expresamente, disminuir el rechazo a pronunciarse prematuramente acerca de las deseables estructuras normativas", 38 ILM, p. 1642, párr. 19.

88 Artículo 1, Ley núm. 95-101, relativa al refuerzo de la protección del medio ambiente del 2 de febrero de 1995, JO, 3 de febrero de 1995.

89 Artículo 4, 3, Ley de Protección del Medio Ambiente Marino. 
Las partes de las convenciones de París y Helsinki de 1992 deben aplicar el Principio del que contamina paga, pero sólo la Convención de París da una definición: "por virtud de los costos de prevención de la polución, control y reducción de medidas para ser soportadas por los contaminadores" (artículo 2, inciso 2, letra b). ${ }^{90}$ Para sobreponerse al problema de contenido y sentido, las partes a la Convención de París han definido el Principio del que contamina paga en el texto de la convención. Esta definición difiere del principio 16 en la "Declaración de Río"que busca un balance entre el Principio del que contamina paga con la obligación de no molestar o entrabar el comercio internacional y la inversión, y es aplicable solamente en un contexto nacional en referencia a autoridades nacionales: "Autoridades nacionales deben esforzarse para promover la asunción de los costos ambientales y el uso de instrumentos económicos tomando en consideración que el contaminador debería, en principio, asumir el costo de la contaminación con relación al interés público y sin distorsionar el comercio internacional y el medio ambiente".*

Aunque las referencias se han hecho al mismo principio, las condiciones para la aplicación del principio son diferentes. Nuevamente la razón parece clara. La aplicación del Principio del que contamina paga en la Convención de París de 1992 es una obligación sobre todos los Estados contratantes ("debe aplicar") pero es restringida geográficamente la Atlántico Noreste. ${ }^{91}$ Esta aplicación del Principio del que contamina paga es significativa en relaciones internacionales, por ejemplo, es de extrema importancia en un reclamo por una parte en contra de la otra. El Principio del que contamina paga en la "Declaración de Río" está concebida para propósitos internos o nacionales y se encuentra dirigida a contaminadores dentro de un Estado, ${ }^{92}$ pero no se encuentra restringida

90 Véase una definición comparable en el artículo 4 (3) (b) de la Convención de Barcelona modificada en 1995.

* Todas las traducciones a los diferentes principios contenidas en la Declaración de Río sobre el Medio Ambiente y el Desarrollo, 1992, que el lector puede encontrar en este texto siguen la versión oficial del Programa de Naciones Unidas para el Medio Ambiente, Oficina Regional para América Latina, véase http://www.rolac.unep.mx/do camb/esp/dr1992.htm (14-10-04) (N. del T.).

91 El mismo punto de vista ha sido incluido en el artículo 4 (2) (b) de la Convención de Barcelona modificada en 1995.

92 Véase también artículo 3 (2) del Protocolo de 1996 de la Convención de Londres sobre Descarga. 
geográficamente, y tienen un alcance potencial mayor en materia de polución. En la Convención de Helsinki de 1992 las partes no definen el Principio del que contamina paga. O los negociadores no alcanzaron consenso en una definición, o ellos se encontraban seguros que por entregar una determinada definición restringirían la potencial aplicación del principio. Aquí la aplicación del principio se encuentra en la discreción con que cada parte, individualmente aplica el principio.

El principio de prevención, reducción y control de la contaminación no debe incrementar la contaminación del mar fuera de la área establecida por la convención o en otras partes del medio ambiente, y ésta devino en una obligación general en las convenciones de París y Helsinki. La Convención de Helsinki es aun más explícita al estatuir (artículo 3, inciso 6): "Además las medidas relevantes no deben llevar o a esfuerzos inaceptables, influencias (strains) acerca de calidad de aire y la atmósfera o en agua, suelo y aguas interiores (groundwater), a inaceptables daños o aumento en la disposición de desechos, o aumentar el riesgo para la salud humana".

Las convenciones de París y Helsinki de 1992 no hacen referencia al "desarrollo sustentable" como Principio de derecho ambiental. Durante las negociaciones de la Convención de París hubo un debate considerable en torno al concepto y su lugar en la convención. La mayoría de las delegaciones han sido de la opinión que el sentido de "desarrollo sustentable" no es claro y quizás muy amplio para encontrar su camino en los textos de la convención. En otras palabras, ellos no han querido abrir una Caja de Pandora. Un compromiso ha sido encontrado al referirse a "manejo sustentable" en el preámbulo de la convención. ${ }^{93}$ Manejo sustentable en este contexto significa que:

Las partes contratantes... reconocen que la acción concertada en el ámbito nacional, regional y global es esencial para prevenir y eliminar la contaminación y obtener manejo sustentable del área marítima, esto es, el manejo de las actividades humanas de manera que los ecosistemas marinos continúen sosteniendo el uso legitimo del mar y continúen alcanzando las necesidades de las generaciones presentes y futuras.

En la ley belga para "Proteger el medio ambiente marino" (artículo 4, párrafo 4), el Principio de manejo sustentable debe ser tomado en consi- 
deración por los gobiernos y los usuarios del mar. Sus acciones deben proteger los ecosistemas y los procesos ecológicos en el medio marino, conservar la biodiversidad y estimular la conservación de la naturaleza:

La aplicación del principio de administración durable en los espacios marinos implique que los recursos naturales son tomados dando una medida suficiente a la disposición de las generaciones futuras y que los efectos de las convenciones del hombre no hace cambiar por las capacidades de absorción del ambiente de los espacios marinos. A este fin, los ecosistemas y los procesos ecológicos necesarios para el buen funcionamiento del medio marino serán protegidos, la diversidad biológica será preservada y la conservación de la naturaleza sea simulada.

"Manejo sostenible" en el mar envuelve un espectro inmenso de protección ambiental y las medidas de conservación que van a ser alcanzadas o que han sido expresadas en mayor detalle en la ley belga, por ejemplo, la posibilidad de establecer pequeñas reservas en el mar (artículos 7, 8 y 9 de la ley). Con el fin de alcanzar el desarrollo sustentable, otros principios y reglas deben ser balanceados como los derechos históricos a pescar por barcos de pesca de otros países o el derecho a pescar como fue acordado en convenios de pesca, el Principio de paso inocente para barcos extranjeros en el mar territorial del Estado costero (sección número 3 de la Convención sobre el Derecho del Mar de Naciones Unidas), el Principio de inmunidad de la soberanía para barcos de propiedad estatal foránea cuando se encuentran envueltos en una actividad gubernamental cuyos servicios son no comerciales (artículo 236 de la Convención sobre el Derecho del Mar de Naciones Unidas). En la ley belga de 1999, aquellos principios de derecho del mar han sido considerados como excepciones o un procedimiento especial para el balance de los "principios ambientales" con el derecho marítimo dentro del país (entre Ministerio de Medio Ambiente y el Ministerio de Agricultura) o en el ámbito internacional (al interior de la Organización Marítima Internacional).

\section{CONFLICTOS ENTRE DIFERENTES PRINCIPIOS DE DERECHO INTERNACIONAL}

Es posible pensar en conflictos potenciales entre "principios de derecho ambiental" como el Principio precautorio o el Principio de la protec- 
ción de las especies y los Principios del libre comercio (por ejemplo, El principio de no-discriminación), desarrollado en el Acuerdo General de Comercio y Tarifas o en el Acuerdo sobre Aplicación de Medidas Sanitarias y Fitosanitarias (SPS) (véase el caso de las Hormonas entre Comunidad Económica Europea y Estados Unidos de América-Canadá) o las prácticas del Estado Europeo Comunitario. ${ }^{94}$

En el caso de las hormonas (Hormones Case) entre la Comunidad Económica Europea y Estados Unidos de América-Canadá, el Cuerpo de Resolución de Disputas (DSB) de la Organización Mundial del Comercio adoptó el 23 de febrero de 1998 un Reporte del Cuerpo de Apelaciones. La Comunidad Económica Europea prohibió la importación de carne de animales que han sido tratadas con seis hormonas de crecimiento porque fue considerada inconsistente o contraria al Acuerdo Sanitario y Fitosanitario (ASF), porque la Comunidad Económica Europea no pudo probar el riesgo particular que estaba en discusión, esto es, el potencial carácter cancerígeno o genotóxico de los residuos de las hormonas. Los estudios generales que se encuentran a disposición de la comunidad muestran un riesgo general de contraer cáncer para cuatro de las seis hormonas pero no fue suficientemente específico. Parece ser que el principio precautorio no pudo ser aplicado como "principio de derecho internacional" en este caso, ya que la Comunidad Económica Europea tendría que haber probado que la prohibición para importar se encuentra fundada en la evaluación de riesgo dentro del significado que para el efecto ha establecido el acuerdo ASF. Tomando en consideración las palabras utilizadas en el texto, y sólo cuando los riesgos se encuentran clara y científicamente probados, puede la Comunidad Económica Europea encontrarse en la situación de aceptar legítimamente la prohibición de la importación en cumplimiento con el convenio ASF. Mientras, Estados Unidos de América y Canadá han sido autorizados para tomar contramedidas de carácter comercial hasta el valor equivalente a sus pérdidas económicas como consecuencia de la prohibición de importar. ${ }^{95}$

94 Véase Renstein, R., "Trade and Environment: The Case for and Against Unilateral Actions", en Lang, W. (ed.), op. cit., nota 53, pp. 223-231; Stevens, C., "Trade and Environment: The PPMs Debate", en Lang, W. (ed.), op. cit., nota 53, pp. 239-24; Scherer, J., "Regional Perspetives on Trade and Environment: The European Union", en Lang, W. (ed.), op. cit., nota 53, pp. 253, 265 y 288.

95 Véase http://www.wto.org/dispute/bulletin.htm;http://europa.eu.int/comm/trade/ miti/dispute/hormones. 
En la disputa "Atún-Delfín" ("Tuna-Dolphin") entre los Estados Unidos de América y México, ${ }^{96}$ el Panel del Acuerdo General de Tarifas y Comercio decidió que las normas jurídicas del Acuerdo General de Tarifas y Comercio no permiten a un país adoptar medidas comerciales con el propósito de intentar obligar al cumplimiento de las propias leyes nacionales en otro Estado, aun cuando el objetivo es proteger la salud animal o los recursos naturales de carácter no renovable.

El Panel de la Organización Internacional del Comercio, en el caso de los camarones (Shrimp Case), la importación de camarones y productos derivados de los camarones fue aplicada por los Estados Unidos de América para proteger las tortugas durante las operaciones de pesca. La prohibición de importar era inconsistente con ciertas reglas del Acuerdo General de Comercio y Tarifas. El panel sentenció: ${ }^{97}$

Consideramos que la mejor manera para que las partes en disputa contribuyan efectivamente a la protección de las tortugas marinas de manera consistente con los objetivos de la Organización Mundial del Comercio, incluyendo desarrollo sustentable, podría ser el alcanzar acuerdos cooperativos acerca de estrategias de conservación integradas cubriendo inter alia, el diseño, implementación y uso de elementos que excluyan a las tortugas en la pesca [TED's en inglés del original] cuando tomamos en consideración las condiciones específicas de las diferentes áreas geográficas.

El Cuerpo de Apelación de la Organización Internacional del Comercio llegó a la misma conclusión al enfatizar que:98 "Los miembros de la

96 En las aguas tropicales del Oceano Pacífico occidental, cardúmenes de atún nadan entre cardúmenes de delfines. Cuando el atún es atrapado en las redes barrederas [de pesca], frecuentemente los delfines son atrapados en [las mismas] redes y frecuentemente mueren cuando no son liberados a tiempo. La Ley de Protección de Mamiferos Marinos de Estados Unidos de América establece las normas de protección de delfines para la flota de pescadores doméstica de EUA y para países cuyos barcos pescan atún en esa parte del Oceano Pacífico. Si un país que se encuentra exportando atún a Estados Unidos de América no puede probar a las autoridades estadounidenses que reúne las condiciones establecidas por las leyes de EUA, el gobierno de este país debe embargar toda importación del pescado. En esta disputa, México fue el país exportador y sus exportaciones a Estados Unidos de América fueron prohibidas.

97 WTO, Report of the Panel on the United States-Import Prohibition of Certain Shrimp Products, 15 de mayo de 1998, 37 ILM, 1998, p. 832 (esp. p. 857).

98 WTO, Report of the Appellate Body on the United States-Import Prohibition of Certain Shrimp Products, 12 de octubre de 1998, 37 ILM, 1998, p. 832 (esp. p. 857). 
Organización Internacional del Comercio son libres de adoptar sus propias políticas del medio ambiente, tanto como ellos cumplan con sus obligaciones y respecto de los derechos de otros miembros bajo las normas de los acuerdos de la Organización Internacional del Trabajo".

La protección de principios ambientales no puede, por tanto, ser vista como un imperativo absoluto. Principios de derecho ambiental y los Principios del Comercio Internacional son parte del desarrollo sustentable, el último para mantener nuestro medio ambiente en un Estado que no destruya el bienestar de las generaciones presentes y la futuras, el primero para alcanzar el bienestar económico del mayor número de personas. Este balance está reflejado en el Principio 12 de la "Declaración de Río":

Los Estados deberían cooperar en la promoción de un sistema económico internacional favorable y abierto que llevara al crecimiento económico y el desarrollo sostenible de todos los países, a fin de abordar en mejor forma los problemas de la degradación ambiental. Las medidas de política comercial con fines ambientales no deberían constituir un medio de discriminación arbitraria o injustificable ni una restricción velada del comercio internacional. Se debería evitar tomar medidas unilaterales para solucionar los problemas ambientales que se producen fuera de la jurisdicción del país importador. Las medidas destinadas a tratar los problemas ambientales transfronterizos o mundiales deberían, en la medida de lo posible, basarse en un consenso internacional.*

\section{CONCLUSIÓN}

Los principios de derecho ambiental han jugado un rol importante en el desarrollo de las normas de derecho internacional ambiental y ha dado lugar a normas jurídicas más específicas. Desde que más y más normas jurídicas y objetivos claros (prohibiciones y reducción de emisiones) han sido aceptadas en tratados, la búsqueda de principios de derecho ambien-

* Todas las traducciones a los diferentes principios contenidas en "Declaración de Río sobre el Medio Ambiente y el Desarrollo, 1992", que el lector puede encontrar en este texto, siguen la versión oficial del Programa de Naciones Unidas para el Medio Ambiente, Oficina Regional para América Latina, véase http://www.rolac.unep.mx/ docamb/esp/dr1992.htm (14-10-04) (N. del T.). 
tal que posean el carácter de norma consuetudinaria ha sido menos esencial. En vez de buscar nuevos principios, el derecho internacional del medio ambiente ha alcanzado un momento para la estabilidad y la implementación de sus principios y normas jurídicas. ${ }^{99}$ Sin embargo, varios obstáculos deben ser sobrepasados. Primero, el sentido de la expresión principios de derecho ambiental puede variar de un instrumento jurídico a otro instrumento jurídico dependiendo de la aplicación de los mismos a un nivel global o regional. Segundo, los principios de derecho ambiental deben ser balanceados la mayoría de las veces frente a otros principios fundamentales y normas de derecho internacional. Este acto de balance se ha convertido en un ejercicio continuo para legisladores que buscan implementar principios de derecho ambiental a la vez que normas jurídicas de derecho ambiental, especialmente cuando principios de derecho internacional largamente establecidos se encuentran envueltos (por ejemplo, pasaje inocente en el derecho del mar o no-discriminación en el caso de acuerdos comerciales). La ley belga de 20 de enero de 1999 para la "protección del medio ambiente y las áreas marítimas" bajo la jurisdicción de Bélgica, es un paso adelante en el proceso continuo para implementar los "principios de derecho ambiental" a través de normas jurídicas y balancear los usos tradicionales de la mar.

99 Véase también Handl, G., "Sustainable Development: General Rules versus Specific Obligations”, en Lang, W. (ed.), op. cit., nota 53, p. 43. 